\title{
Job Stressors and Management Tactics of Female Employees in Chain Retail Business
}

\author{
SHAO Aihua \\ School of Economics and Management \\ Shangdong women's college \\ Ji'nan, China \\ e-mail: newguihua@yahoo.com.cn
}

\begin{abstract}
The low salary, the fastidious customers, the heavy work, the unfixed working hours, those characteristics of job bring great pressure to the female employees in chain retail business. Choosing the female employees in Ji'nan chain retail business as the investigation object, exploring the job stressors of female employees in chain retail business by the method of interview and questionnaire. The statistic results show that the job stressors of female employees in chain retail business mainly include the work itself, occupation development and work-family conflict. Finally, on the basis of the job stressors of female employees in chain retail business, the document put forward of the stress management tactics at the individual level and organizational level.
\end{abstract}

Keywords- chain retail business; female employees; job stressors; management tactics.

\section{INTRODUCTION}

Chain retail business in China, although less than 20 years of development time, it has become one of the most development potential business in the domestic. For the majority female employees in chain retail business, the heavy work, picky customer, low wages and unfixed working hours and so on, which is very easy to bring the greater work pressure to them ${ }^{1}$. If the individual regulation and organization management is not in place, excessive work pressure mostly cause some negative effects to the individual: such as physical and mental ill, performance decline, low job satisfaction, and even resignation, which is one of the main reasons of higher staff mobility in chain retail business.

Therefore, research on retailing women staffs' work pressure with analyzing its job stressors and coping and management tactics at the individual level and organizational level, for the creation of a harmonious working environment, reduction the rate of employee turnover, maintaining female employees' physical and mental health and improving their job performance, and to improve the customer satisfaction and loyalty, and promoting the development of the chain retail business, has important practical significance and theoretical value.

\section{THE LITERATURE REVIEW AND PROBLEM}

Chain retail business belongs to the service industry, and its product needs the staffs' service to load, to a large extent, the normativeness and unity of the products and services are decided by the staff. Therefore, whether the chain retail business can obtain expected success or not, the key lies in the effectiveness of its staff management. The domestic chain retail with labor intensive, the low salary, the intensity of work, unfixed working hours, whose characteristics easily become the job stressors of female employees. From the perspective of human resource management, chain retail enterprises at present have many problems ${ }^{2}$, such as the lack of employee occupation development planning, unscientific compensation incentive, unsystematic training, injustice assessment, which can't correctly guidance and effectively relief the female individual work pressure, but also they increase women staffs' job stressors.

Researchers on the job stressors of female employees are mainly Li Yongtai and Guo Zongjun. Guo Zongjun ${ }^{3}$ suggests that women staffs' job stressors are mainly as follows: "work on time", "income", "education", "work load" etc. Li Yongtai $^{4}$ studies suggest that women, in addition to the same work pressure source with men, have their unique job stressors: gender discrimination, family-work conflicts, social and cultural factors, women's own negative personality. At present, domestic researches on job stressors of female employees are not refinement for industry classification. Job stressors of female employees have different characteristics in different industries, so it needs to study the job stressors of female employees in refining industry or post that the management tactics proposed would be more targeted and practical value.

\section{JOB STRESSORS OF FEMALE EMPLOYEES IN CHAIN RETAIL BUSINESS}

We selected the Ji'nan typical chain retail enterprises such as the INZONE, WAL-MART, RT-Mart and Tesco, Shuyu civilian pharmacies, with the method of interview and questionnaire, and investigated on job stressors and coping tactics of female employees, organizational management tactics. The interview object is the senior women managers and junior female employees, 10 senior women managers and 25 junior female employees. Based on the analysis of interview data, referring to Cooper's $\mathrm{OSI}^{5}$, we design the scale of job stressors and management tactics for female employees in chain retails. The branch job stressors scale includes the work itself characteristics, organization atmosphere, occupation development and interpersonal relationship, work-family conflicts. Through email and on-site questionnaires, 200 questionnaires were distributed, 191 returned questionnaires, 185 valid questionnaires. SPSS 
was used for the descriptive statistical analysis of work pressure sources.

TABLE 1 DESCRIPTIVE STATISTICS OF FEMALE EMPLOYEES' JOB STRESSORS IN CHAIN RETAILS

\begin{tabular}{ccc}
\hline Job stressors & Proportion & Sorting \\
\hline $\begin{array}{c}\text { Work itself } \\
\text { characteristics }\end{array}$ & $87 \%$ & 1 \\
\hline $\begin{array}{c}\text { Organization } \\
\text { atmosphere }\end{array}$ & $29.2 \%$ & 4 \\
\hline $\begin{array}{c}\text { Occupation } \\
\text { development }\end{array}$ & $71.4 \%$ & 2 \\
\hline $\begin{array}{c}\text { Interpersonal } \\
\text { relationship }\end{array}$ & $16.2 \%$ & 5 \\
\hline Work-family conflicts & $48.1 \%$ & 3
\end{tabular}

Through the analysis of the statistic data, the work itself features become the first job stressor of female employees in chain retail business, followed by the occupation development and work-family conflicts, but organizational atmosphere and interpersonal relationships exercise relatively smaller effect on female staff working pressure in chain retail business. Combined with the interview data, the next we will analyze the statistical results in detail.

\section{[1] Work Itself Characteristics}

The work itself features as the first source of job stress, mainly because chain retail business belongs to the service industry, service principles, such as "customer first", "service with a smile", make employees feel that they aren't respected, then they are psychological imbalance in the process of service; secondly, irregular work time. Chain retail enterprises' operating time is not from nine to five, from Monday to Friday, so the staff work according to the needs of the job sometimes in the morning, sometimes at night. Even on weekends, holidays, they are more busy and no leisure. This work forces them to give up a lot of time and opportunity with friends and family together for emotional support, thus leads to produce job stress; Thirdly, highly repetitive and fixed work environment in chain retail business, which is easy to cause female staff to be fatigue, anger and depression. According to the research at the Queensland University of Technology's Institute of Health and Biomedical Innovation in Australia, open office environment is easy to be confused in mind, and personal exposure to other people's field of vision will make people feel insecurity and more pressure.

The above analysis shows why the work itself characteristics are the first job stressors of female employees in chain retail business. It is necessary to focus on management of this job stressor in the design of pressure management tactics.

\section{[2] Occupation Development}

Occupation development is the second factors affecting female staff on working pressure. Whether can staff realize occupation expectation and get satisfaction in occupation life, will affect them on working pressure. For the general staff, occupation development pressure mainly comes from the occupation security, improvement of skills, promotion and occupation prospect, social status, etc.

TABLE I. Occupation security

Occupation security mainly includes salary, welfare, work environment etc. The basic purpose of job is to get existence security and to raise the living standard. Without reliable occupation security, psychological burden will be increased, then resulting in the working pressure. Female employees in chain retail business have low wages and the price are soaring today, that the wages of the employees can only maintain the basic life. Lower occupation security level leads to the working pressure.

TABLE II. Improvement of skills

Job skill requirements in chain retails are generally low, with simple training, and most people can meet job requirement. Therefore, most posts in chain retails are easily replaced, and technical content of job is low, which results in the higher occupation crisis for employees, then more work pressure.

\section{TABLE III. Occupation prospect}

Most employees expect to realize their occupation development with personal effort. Fewer job opportunities, the bleak of occupation prospect, or the inequality of organization performance evaluation leading to poor promotion, which will cause the employees dissatisfaction and mental burden, then resulting in the job stress. There are more grass-roots women employees and relatively less management position in chain retails, so the promotion channel is narrow that female employees have less occupation opportunities. For older women staffs, if not taking management positions, it will be difficult to do the work with long time standing. Therefore, most female staffs feel job stress because of less confidence and safety on the occupation prospect.

\section{TABLE IV. Social status}

Assumption of "Social person" assumes that people have a desire for self-actualization and need to be recognized by the society. Therefore, staffs are very concerned about the social status what job brings. At present, the social status is not high for practitioners in chain retail business, which may also reduce their commitment and enthusiasm to work, then having a certain psychological burden and resulting in the formation of working pressure.

\section{[3] Work-family Conflicts}

Work-family conflicts are the third job stressor of female employees in chain retail business. Female employees are employee, leader or subordinate in organization and they are the mother, wife, daughter at home. Sometimes these characters are conflicts in time and space. When family member is sick, it will scatter attention and involvement to the work. Excessive fatigue in work will affect the performance of the family responsibility. The characteristics of irregular working hours for female employees in chain retails interfere them with fulfilling their family, social role, While it is considered that women should contribute more to the family in the traditional culture perspective. The conflicts between occupation roles and family roles are easy to produce greater psychological pressure. 


\section{[4] Organization Atmosphere and Interpersonal} Relationship

The organization atmosphere and interpersonal do not constitute a source of female employees' job stress in chain retails. This indicates that the organization culture, organization structure in chain retails are relatively stable, so they aren't the main job stressors. In chain retail business, the staff is independent of facing the customer demands; Hence mutual cooperation and competition aren't very prominent. So, the interpersonal is relatively simple, which won't cause job stress on female employees.

\section{PERSONAL AND ORGANIZATIONAL MANAGEMENT TACTICS}

According to the job stressors of female employees in chain retail business, we adopt related management tactics from the individual level and organizational level.

\section{[5] Personal Management Tactics}

\section{TABLE V. Cognitive regulation}

The way people choose to deal with pressure depends on the individual personality and cognitive. The positive cognitive is far more effective than the negative on solving the problem. For the problem of work-family conflicts, right cognitive plays an important role in resolving the pressure source. Above all, defining the priority between family roles and work roles, distinguish the primary from the secondary, which is conductive to their reasonable arrangement on time and energy; secondly, attitude towards the role conflict is tolerant and peaceful. Accepting unpleasant life, unperfected work, not to give up the responsibility to the family and the pursuit for the work. With the restriction on limited time, energy, female employees should adjust expectations and do not excessively criticism for themselves.

TABLE VI. Physiological regulation

Diet and exercise are effective methods to ease the pressure. For the women staffs in chain retail business, facing the work pressure, they should learn to regulate themselves when they are unable to change the status quo. The scientific diet not only can guarantee the health of the body but also can improve the ability of coping with stress. Some foods can relieve pressure: tomatoes, whole grains, green vegetables; Sports also have very good effect on individual decompression. Physical exercise, such as swimming, yoga, rope skipping, is beneficial to the improvement of the body health, enhancing the joy of spirit, and then relieving physical and mental pressure.

TABLE VII. Time management

Appropriate time-management can help the successful completion of the task in the given time. For example, work-family conflict of female employees in chain retails, if they can plan the time in advance, conflict between work and family will be reduced, to avoid resulting in some work pressure.

\section{TABLE VIII. Occupation career planning}

An effective way of resolving the work-family conflict for retails women is to plan their own occupation career. Analyzing objectively in the aspects of their own interest, ability, personality etc. then, according to their age, marital status and occupation development stage, the female employees position themselves accurately, establishing occupation goals for themselves, and plan good occupation development path.

\section{[6] Rrganizational ManagementTactics}

\section{TABLE IX. Job rotation}

Job rotation refers to mobilize employees working positions in the same department or between different departments. High repeatability of working content and a fixed work place in chain retails, which is very easy to cause the female staff dullness and negative mood, and then produce job stress. Through job rotation, employees can work in different positions or departments, which can enrich working content and reduce the dullness, but also can make the employees master some skills, expanding the occupation development path. So job rotation can mobilize the enthusiasm of the staff and reduce the job stress .

\section{TABLE X. Occupation career management}

Occupation development is one of the main job stressors of female employees in chain retails. To solve the problem is an effective way to alleviate the job stress. Organizational management for employees occupation career can combine the organization's goal with the personal work objectives together, and relieve the job stress from uncertainty, insecurity occupation career. Occupation career management of employees, enterprises need to help the individuals analyze themselves, providing the available information of occupation development path, as well as formulate the related organization training and individual learning plans for the female staffs.

\section{TABLE XI. Employee assistance program}

Employee assistance program (EAP) is organized as a comprehensive service for employees, including personal life, work issues and organizational development. Personal life issues include health problems, interpersonal relationship, family relationship, economic problems, emotional distress and anxiety, alcoholism; Work issues include work in the sense of fairness, work-life balance, work pressure and other related issues; Organization development refers to the human resources management method that enables the organization to obtain the maximum benefit from the EAP. If the organization can well carry out the EAP project for staffs, it will give employees help and support greatly from psychological and emotional, so that they can learn how to prevent, face and solve the sources of job stress.

\section{ACKNOWLEDGMENT}

This research was financially supported by Shandong Province female human resources development and management research base open fund project " job stress and coping strategies of female employees in chain retails -survey of based on Ji'nan chain retails " (Grant NO.YB201203).

\section{REFERENCES}

[1] Yang Hua and Li Lei, The problem of frontline employee turnover in retail chain enterprise, Enterprise Vitality, vol.6, pp. 27-29, 2009. 
[2] Wang Wenchao, On the mode of human resource management in chain enterprise, Modern Business Trade Industry, vol.19, pp. 44-45, 2007.

[3] Guo Zongjun, Investigation of female occupation pressure source from work-family conflict, Chinese Journal of Tissue Engineering Research, vol.10, pp. 66-68, 2006.
[4] Li Yongtai, Investigation on the characteristics of job stress and relief measures of women employees, Journal of Guizhou University(Social Sciences), vol.24, pp. 65-70, 2006

[5] Cooper, C.L, and Marshall, J. Understanding Executive Stress[M], Macmillan Press, pp. 101-112, 1978. 